\title{
Craniofacial changes and symptoms of sleep-disordered breathing in healthy children
}

\author{
Maria Christina Thomé Pachecoํ․ Bruna Santos Fiorott² ${ }^{2}$ Nathalia Silveira Finck², Maria Teresa Martins de Araújo ${ }^{3}$
}

DOI: http://dx.doi.org/10.1590/2176-9451.20.3.080-087.oar

Introduction: The main cause of mouth breathing and sleep-disordered breathing (SDB) in childhood is associated with upper airway narrowing to varying degrees. Objective: The aim of this study was to assess the prevalence of morphological and functional craniofacial changes and the main clinical symptoms of SDB in healthy children. Methods: A cross-sectional observational study was conducted. A sample comprising 687 healthy schoolchildren, aged 7-12 years old and attending public schools, was assessed by medical history, clinical medical and dental examination, and respiratory tests. The self-perceived quality of life of mouth breathing children was obtained by a validated questionnaire. Results: Out of the total sample, 520 children were nose breathers (NB) while 167 (24.3\%) were mouth breathers (MB); 32.5\% had severe hypertrophy of the palatine tonsils, $18 \%$ had a Mallampati score of III or IV, 26.1\% had excessive overjet and 17.7\% had anterior open bite malocclusion. Among the MB, 53.9\% had atresic palate, 35.9\% had lip incompetence, $33.5 \%$ reported sleepiness during the day, $32.2 \%$ often sneezed, $32.2 \%$ had a stuffy nose, $19.6 \%$ snored, and $9.4 \%$ reported having the feeling to stop breathing while asleep. However, the self-perception of their quality of life was considered good. Conclusion: High prevalence of facial changes as well as signs and symptoms of mouth breathing were found among health children, requiring early diagnosis and treatment to reduce the risk of SDB.

Keywords: Malocclusion. Mouth breathing. Quality of life.

Introdução: a principal causa da respiração bucal e dos distúrbios respiratórios do sono (DRS) está associada ao estreitamento das vias aéreas superiores, em diferentes graus. Objetivo: avaliar a prevalência de alterações morfológicas e funcionais da face e os principais sintomas clínicos de DRS em crianças saudáveis. Métodos: estudo transversal, observacional, com amostra de 687 escolares saudáveis, provenientes de escolas públicas, com idades entre 7 e 12 anos. Foram avaliados pela história clínica, exame clínico médico e odontológico e testes respiratórios. A autopercepção da qualidade de vida dos escolares com respiração bucal foi obtida por meio de um questionário validado. Resultados: na amostra total, 520 crianças eram respiradoras nasais (RN) e 167 (24,3\%) eram respiradoras bucais (RB); 32,5\% tinham hipertrofia das amígdalas palatinas, 18\% tinham índice Mallampati obstrutivo (III e IV); 26,1\% tinham overjet exagerado e 17,7\%, mordida aberta anterior. Entre os RB, 53,9\% tinham palato atrésico; 35,9\% com ausência de selamento labial; 33,5\% relataram sonolência diurna; $32,2 \%$, espirros frequentes; $32,2 \%$, nariz entupido; $19,6 \%$ roncavam e $9,4 \%$ relataram ter a sensação de parar de respirar durante o sono. Entretanto, a autopercepção da qualidade de vida desses escolares foi considerada boa. Conclusão: foi encontrada alta prevalência de alterações faciais, de sinais e de sintomas clínicos de respiração bucal nos escolares saudáveis examinados, necessitando diagnóstico e tratamento para reduzir o risco de DRS.

Palavras-chave: Má oclusão. Respiração bucal. Qualidade de vida.

${ }^{1}$ Full professor, Dental Clinic department, Universidade Federal do Espírito Santo, UFES, Vitória, Brazil.

${ }^{2} \mathrm{MSc}$ in Dental Clinic, Universidade Federal do Espírito Santo, Vitória, ES. Brazil.

${ }^{3}$ Adjunct professor, Physiological Sciences department, Universidade Federal do Espírito Santo, Vitória, ES, Brazil.
How to cite this article: Pacheco MCT, Fiorott BS, Finck NS, Araújo MTM. Craniofacial changes and symptoms of sleep-disordered breathing in healthy children. Dental Press J Orthod. 2015 May-June;20(3):80-7.

DOI: http://dx.doi.org/10.1590/2176-9451.20.3.080-087.oar

Submitted: July 04, 2014 - Revised and accepted: November 25, 2014

" The authors report no commercial, proprietary or financial interest in the products or companies described in this article.

Contact address: Maria Christina Thomé Pacheco

E-mail: christp@terra.com.br 


\section{INTRODUCTION}

Sleep-disordered breathing (SDB) varies in severity; ranging from snoring, upper airway resistance syndrome (UARS) and, the most severe, obstructive sleep apnea (OSA). In contrast with SDB in adults, which is usually associated with obesity, the pediatric population experiences these disorders in association with hypertrophy of tonsils and adenoids, allergies, frequent colds and mouth breathing. ${ }^{1-7}$

The association between mouth breathing and SDB has been described as a public health concern because of the clinical impact of these disorders on craniofacial development and growth, delay in height and weight growth and behavioral changes, such as hyperactivity, irritability, restless sleep, impaired concentration and reduced school performance..$^{8,9,10}$

SDB during childhood is rather frequent. However, its signs are not always appropriately recognized or even diagnosed. Anamnesis should tackle aspects of sleep pattern, especially in mouth-breathing children..$^{2-5}$

With regards to the impact on craniofacial growth and development, the persistence of mouth breathing throughout the growth stage causes specific facial changes, such as vertical increase of the lower face; narrow palate; dental malocclusions, mainly anterior open bite and posterior crossbite; lip incompetence; short upper lip and everted lower lip; hypotonic masticatory muscles; and changes in tongue posture at resting, swallowing, speaking and chewing. ${ }^{8-11}$

Because mouth breathing is one of the predisposing factors to SDB in children, this study aims to assess the prevalence of the morphological and functional craniofacial changes and the main nasal and sleep symptoms reported by healthy schoolchildren aged between 7 and 12 years old.

\section{MATERIAL AND METHODS}

A cross-sectional, observational study with a quantitative epidemiological approach was conducted with 687 schoolchildren aged between 7 and 12 years old. The subjects were from eight different elementary schools, each school randomly selected from each one of the eight micro regions of the city Vitória, ES, Brazil. The selection of healthy schoolchildren, rather than patients seeking medical or dental care, was due to lack of a preventive policy for health problems in Brazilian public schools. Moreover, most parents or legal guardians only seek health care when the child already has some type of disease symptom.
All schoolchildren were invited to participate; however, we examined only those whose parents or legal guardians had signed the informed consent form (ICF) allowing them to participate. Exclusion criteria were as follows: unerupted first molars, previous orthodontic treatment, patients under medical care and presenting some type of neurological, neuromuscular or motor changes that would hinder their participation.

This study was approved by Universidade Federal do Espírito Santo Institutional Review Board and had permission from local City Hall to be conducted in the public schools.

The examiners (two orthodontists and two Otolaryngology internship medical residents) underwent calibration. Average values for inter- and intraexaminer agreement of 0.84 and 0.93 were obtained by Kappa test.

A survey instrument was designed to collect the main morphological and functional clinical characteristics of the face, occlusion and upper airways. In order to have some of their facial features assessed, children were carefully observed in their natural state, without letting them realize that they were being examined. Each child was assessed under natural light, sitting on a chair in front of the researcher who wore biosafety equipment and disposable material for clinic examination.

The medical residents examined facial and airway features (seeking for size, coloration, nasal secretions, obstruction and edema). Dental students examined craniofacial features, malocclusion and performed the respiratory tests. The mirror test was performed by placing a graded mirror under the nose, and a halo of water vapor was marked after the third normal expiration. Two lip seal tests were also performed for three minutes each, one using a sticky tape to close the lips and the other with water into the child's mouth. At the end of the clinical examination, a diagnostic impression was established by both medical and dental groups, concerning the child's respiratory function. Each child was classified as mouth breather $(\mathrm{MB})$ or nose-breather (NB), distinguishing between chronic and occasional mouth breathers.

Only children diagnosed as mouth breathers answered a structured questionnaire titled "The mouth breather quality of life questionnaire", developed ${ }^{11}$ and validated ${ }^{12}$ by Ribeiro. ${ }^{11,12}$ The questionnaire comprises 51 questions divided into seven fields to assess mouth breathers' quality of life in terms of nasal problems, sleeping problems, eating disorders, dentition and es- 
thetics, education, communication and atopy. An ordinal value was associated to the sequential answer scale: 0 (zero) for "no/never", 1 or 2 for "hardly ever", 3 for "once in a while", 4 or 5 for "often", 6 for "always", with the highest score referring to the worst quality of life. However, in the present study, we focused mainly on the fields "nasal problems" and "sleeping problems" to assess the schoolchildren self-perception on some of the main symptoms of SDB during childhood.

\section{Statistical analysis}

Statistical tests for comparison of two proportions were performed considering two populations with a Bernoulli distribution and parameters $p_{1}$ and $p_{2}$. For larger samples, the proportions were considered an approximation of the normal distribution $N(0.1)$. It was assumed that the null hypothesis was $p_{1}=p_{2}$. An alpha level of $5 \%$ and a confidence interval of $95 \%$ were adopted. The statistical programs used were Action (with the system developed under the R platform) and IBM SPSS Statistics 19.

\section{RESULTS}

The initial sample comprised 687 healthy schoolchildren of which 329 (47.9\%) were males and 358 (52.1\%) were females. The majority of schoolchildren aged between 8 and 9 years old (42.9\%). The distribution per school varied according to the size of the school and the survey acceptance through the signing of an ICF by the parent/legal guardian. From the total sample, 167 (24.3\%) schoolchildren were diagnosed as MB while $520(75.7 \%)$ were diagnosed as NB.

Table 1 shows the main alterations on the upper airways (UA). The occurrence of palatine tonsils (grades III and IV) and Mallampati classes II, III and IV were dominant in MB schoolchildren. These data are relevant and point to the predominance of narrowed airways in $\mathrm{MB}$ schoolchildren.

Changes in nasal septum and turbinate hypertrophy were also more prevalent in the MB group, highlighting edema (36.5\%), nasal septal deviation (19.2\%) and turbinate hypertrophy (73.1\%). Some children simultaneously experienced edema and deviated nasal septum. The presence of tonsils grade III, Mallampati class III, edema of the nasal septum and turbinate hypertrophy were relevant findings for the MB group $(\mathrm{p}<0.050)$.
Table 2 describes the most important facial features assessed. Although most schoolchildren have a normal facial type (mesofacial), there is a high incidence of the dolichofacial pattern (34.7\%) in the MB group. This pattern was perceived in only $11.7 \%$ of the NB group. Convex facial profile was predominant $(50.9 \%)$ in the $\mathrm{MB}$ group. Absence of lip competence was higher in the $\mathrm{MB}$ group (35.9\%) in comparison to the NB group in which it was only $2.5 \%$.

The most relevant findings in the $\mathrm{MB}$ group $(p<0.050)$ were dolichofacial pattern and the absence of lip competence.

Table 3 shows the prevalence of malocclusion in schoolchildren. The MB group presented a prevalence of deep overbite, anterior open bite, posterior crossbite, pronounced overjet, Angle Class II molar relationship and atresic palate. The relevant findings $(p<0.050)$ were overjet greater than $4 \mathrm{~mm}$ and atresic palate.

On the mirror test (Table 4), most children (95.3\%) showed a halo of water vapor larger than $30 \mathrm{~mm}$, which demonstrates lack of nasal obstruction. However, when assessing the $\mathrm{MB}$ group, the prevalence of a halo smaller than $30 \mathrm{~mm}$ (14.4\%) was statistically significant, which suggests that the presence of mouth breathing was caused by nasal obstruction.

On both lip seal tests, using sticky tape $(48.5 \%)$ or water retention $(46.1 \%)$, the prevalence of lip seal for less than 3 minutes was significant for the MB group, which suggests difficulty breathing through the nose.

The results yielded from the quality of life questionnaire applied to mouth breathers are shown in Table 5 . They show the seven fields surveyed and the overall score. Higher scores mean worse quality of life, while lower scores show better quality of life. Both mean and median values in all fields were below half the maximum value possible for each field, showing good assessment of quality of life. However, taking into account the wide variability of the standard deviation, one can see that a great part of children reported having a not so good quality of life.

\section{DISCUSSION}

The presence of hypertrophied palatine tonsils was remarkable for the entire sample, with predominance of grades I and II (non obstructive) in the NB group and grades III and IV (obstructive) in the MB group. Palatine tonsils were classified according to Brodsky: ${ }^{13}$ grade I (tonsils take 
Table 1 - Prevalence of upper airway (UA) problems in nose breathers and mouth breathers schoolchildren.

\begin{tabular}{|c|c|c|c|c|c|c|c|}
\hline & \multicolumn{4}{|c|}{ Groups } & \multirow{3}{*}{ p value } & \multicolumn{2}{|c|}{ Total } \\
\hline & \multicolumn{2}{|c|}{ Nose breathers } & \multicolumn{2}{|c|}{ Mouth breathers } & & \multirow{2}{*}{ n } & \multirow{2}{*}{$\%$} \\
\hline & $n$ & $\%$ & $n$ & $\%$ & & & \\
\hline \multicolumn{8}{|c|}{ Palatine tonsils } \\
\hline 1 & 83 & 16.0 & 20 & 12.0 & 0.230 & 103 & 15.0 \\
\hline$\|$ & 281 & 54.0 & 80 & 47.9 & 0.167 & 361 & 52.5 \\
\hline III & 138 & 26.5 & 59 & 35.3 & $0.025^{\star}$ & 197 & 28.7 \\
\hline IV & 18 & 3.5 & 8 & 4.8 & 0.434 & 26 & 3.8 \\
\hline \multicolumn{8}{|c|}{ Mallampati score } \\
\hline । & 221 & 42.5 & 41 & 24.5 & $0.000^{*}$ & 262 & 38.2 \\
\hline ॥ & 219 & 42.1 & 82 & 49.1 & 0.113 & 301 & 43.8 \\
\hline III & 71 & 13.7 & 37 & 22.2 & $0.009 *$ & 108 & 15.7 \\
\hline IV & 9 & 1.7 & 7 & 4.2 & 0.067 & 16 & 2.3 \\
\hline \multicolumn{8}{|l|}{ Nasal septum } \\
\hline Normal & 302 & 58.1 & 67 & 40.1 & $0.000 *$ & 369 & 53.7 \\
\hline Swollen & 119 & 22.9 & 61 & 36.5 & $0.000^{*}$ & 180 & 26.2 \\
\hline Deviated & 86 & 16.5 & 32 & 19.2 & 0.492 & 118 & 17.2 \\
\hline $\begin{array}{l}\text { Swollen/ } \\
\text { deviated }\end{array}$ & 13 & 2.5 & 7 & 4.2 & 0.383 & 20 & 2.9 \\
\hline \multicolumn{8}{|c|}{ Turbinate hypertrophy } \\
\hline No & 223 & 42.9 & 45 & 26.9 & $0.000 *$ & 268 & 39.0 \\
\hline Yes & 297 & 57.1 & 122 & 73.1 & $0.000 *$ & 419 & 61.0 \\
\hline
\end{tabular}

* Statistically significant $(p<0.05)$.

Table 2 - Prevalence of facial features in nose breathers and mouth breathers schoolchildren

\begin{tabular}{|c|c|c|c|c|c|c|c|}
\hline & \multicolumn{4}{|c|}{ Groups } & \multirow{3}{*}{ p value } & \multicolumn{2}{|c|}{ Total } \\
\hline & \multicolumn{2}{|c|}{ Nose breathers } & \multicolumn{2}{|c|}{ Mouth breathers } & & \multirow{2}{*}{ n } & \multirow{2}{*}{$\%$} \\
\hline & $n$ & $\%$ & $n$ & $\%$ & & & \\
\hline \multicolumn{8}{|l|}{ Facial type } \\
\hline Mesofacial & 404 & 77.7 & 100 & 60.5 & 0.000 * & 505 & 73.5 \\
\hline Dolichofacial & 61 & 11.7 & 58 & 34.7 & $0.000 *$ & 119 & 17.3 \\
\hline Brachyfacial & 55 & 10.6 & 8 & 4.8 & $0.000^{*}$ & 63 & 9.2 \\
\hline \multicolumn{8}{|l|}{ Facial profile } \\
\hline Straight & 367 & 70.6 & 75 & 44.9 & $0.000 *$ & 442 & 64.3 \\
\hline Convex & 142 & 27.3 & 85 & 50.9 & $0.000^{*}$ & 227 & 33.1 \\
\hline Concave & 11 & 2.1 & 7 & 4.2 & 0.144 & 18 & 2.6 \\
\hline \multicolumn{8}{|l|}{ Lip competence } \\
\hline Present & 507 & 97.5 & 107 & 64.1 & $0.000^{*}$ & 614 & 89.3 \\
\hline Absent & 13 & 2.5 & 60 & 35.9 & $0.000 *$ & 73 & 10.7 \\
\hline
\end{tabular}

* Statistically significant $(p<0.05)$. 
Table 3 - Prevalence of malocclusion in nose breathers and mouth breathers groups

\begin{tabular}{|c|c|c|c|c|c|c|c|}
\hline & \multicolumn{4}{|c|}{ Groups } & \multirow{3}{*}{$p$ value } & \multicolumn{2}{|c|}{ Total } \\
\hline & \multicolumn{2}{|c|}{ Nose breathers } & \multicolumn{2}{|c|}{ Mouth breathers } & & \multirow{2}{*}{$n$} & \multirow{2}{*}{$\%$} \\
\hline & $n$ & $\%$ & $n$ & $\%$ & & & \\
\hline \multicolumn{8}{|l|}{ Overbite } \\
\hline Normal & 271 & 52.1 & 73 & 43.7 & 0.072 & 344 & 50.1 \\
\hline Moderate & 135 & 26.0 & 45 & 26.9 & 0.897 & 180 & 26.2 \\
\hline Severe & 24 & 4.6 & 9 & 5.4 & 0.832 & 33 & 4.8 \\
\hline Does not apply & 90 & 17.3 & 40 & 24.0 & 0.070 & 130 & 18.9 \\
\hline \multicolumn{8}{|l|}{ Open bite } \\
\hline Absent & 437 & 84.1 & 128 & 76.6 & $0.025^{\star}$ & 565 & 82.3 \\
\hline Top & 40 & 7.7 & 18 & 10.8 & 0.274 & 58 & 8.4 \\
\hline Present & 43 & 8.2 & 21 & 12.6 & 0.121 & 64 & 9.3 \\
\hline \multicolumn{8}{|l|}{ Crossbite } \\
\hline Absent & 417 & 80.2 & 137 & 82.0 & 0.909 & 554 & 80.6 \\
\hline Anterior & 28 & 5.4 & 4 & 2.4 & 0.165 & 32 & 4.7 \\
\hline Posterior & 67 & 12.8 & 24 & 14.4 & 0.689 & 91 & 13.2 \\
\hline Ant/Posterior & 8 & 1.6 & 2 & 1.2 & 0.997 & 10 & 1.5 \\
\hline \multicolumn{8}{|l|}{ Overjet } \\
\hline $1-2 \mathrm{~mm}$ & 341 & 65.6 & 88 & 52.7 & $0.004^{\star}$ & 429 & 62.4 \\
\hline 3-4 mm & 109 & 21.0 & 48 & 28.7 & 0.051 & 157 & 22.9 \\
\hline$>4 \mathrm{~mm}$ & 11 & 2.1 & 11 & 6.6 & $0.009 *$ & 22 & 3.2 \\
\hline Does not apply & 59 & 11.4 & 20 & 12 & 0.943 & 79 & 11.5 \\
\hline \multicolumn{8}{|c|}{ Molar relationship } \\
\hline Class I & 409 & 78.7 & 123 & 73.7 & 0.098 & 532 & 77.5 \\
\hline Class II & 92 & 17.7 & 35 & 21.0 & 0.400 & 127 & 18.5 \\
\hline Class III & 19 & 3.7 & 9 & 5.4 & 0.460 & 28 & 4.1 \\
\hline \multicolumn{8}{|l|}{ Palate } \\
\hline Normal & 328 & 63.1 & 77 & 46.1 & $0.000 *$ & 405 & 58.9 \\
\hline Atresic & 192 & 36.9 & 90 & 53.9 & $0.000 *$ & 282 & 41.0 \\
\hline TOTAL & 520 & 100.0 & 167 & 100.0 & & 687 & 100.0 \\
\hline
\end{tabular}

* Statistically significant $(p<0.05)$

up 25\% of the oropharyngeal airway space), grade II (25 to $50 \%$ ), grade III (50 to $75 \%$ ) and grade IV (more than 75\% of the oropharyngeal airway space).

The American Academy of Pediatrics ${ }^{1}$ highlights hypertrophy of palatine tonsils as a significant risk factor for the development of SDB during childhood. Nevertheless, the severity of SDB is not always related to the size of tonsils. Many children with significant hypertrophy do not present breathing disorders related to sleep. Therefore, other risk factors, such as changes in facial morphology or alterations in breathing control during sleep, may coexist. For this reason, we surveyed most morphological, craniofacial and upper airway changes related to SDB in children.
Unlike tonsils grades that identify lateral airway narrowing, the Mallampati score identifies vertical airway narrowing. A modified Mallampati score, ${ }^{14,15}$ in total mouth opening, with the tongue relaxed and lying in the oral cavity, was used. In the NB group, there was a predominance of class I Mallampati, which suggests wide airways. In the MB group, Mallampati classes III and IV (obstructive) were predominant, which suggests narrow or small airways. ${ }^{6,7}$ The presence of a swollen or deviated nasal septum (59.9\%) in the MB group was striking, as it contributes to increased mouth breathing. Palombin et $\mathrm{al}^{3}$ recommend investigating any type of nasal obstruction, turbinate hypertrophy, Mallampati score, size of palatine tonsils, long face, genetic syndrome patterns 
Table 4 - Prevalence found for respiratory tests in nose breathers and mouth breathers schoolchildren.

\begin{tabular}{|c|c|c|c|c|c|c|c|}
\hline & \multicolumn{4}{|c|}{ Groups } & \multirow{3}{*}{ p value } & \multicolumn{2}{|c|}{ Total } \\
\hline & \multicolumn{2}{|c|}{ Nose breathers } & \multicolumn{2}{|c|}{ Mouth breathers } & & \multirow{2}{*}{$n$} & \multirow{2}{*}{$\%$} \\
\hline & n & $\%$ & $n$ & $\%$ & & & \\
\hline \multicolumn{8}{|l|}{ Mirror test } \\
\hline Halo > $30 \mathrm{~mm}$ & 512 & 98.5 & 143 & 85.6 & $0.000 *$ & 655 & 95.3 \\
\hline Halo < $30 \mathrm{~mm}$ & 8 & 1.5 & 24 & 14.4 & $0.000^{*}$ & 32 & 4.7 \\
\hline \multicolumn{8}{|l|}{ Lip seal test } \\
\hline For 3 minutes & 510 & 98.1 & 86 & 51.5 & $0.000 *$ & 596 & 86.8 \\
\hline Less than 3 minutes & 10 & 1.9 & 81 & 48.5 & $0.000 *$ & 91 & 13.2 \\
\hline \multicolumn{8}{|l|}{ Water retention test } \\
\hline For 3 minutes & 511 & 98.3 & 90 & 53.9 & $0.000^{*}$ & 601 & 87.5 \\
\hline Less than 3 minutes & 9 & 1.8 & 77 & 46.1 & $0.000^{*}$ & 86 & 12.5 \\
\hline TOTAL & 520 & 100.0 & 167 & 100.0 & & 687 & 100.0 \\
\hline
\end{tabular}

* Statistically significant $(p<0.05)$

Table 5 - Median, mean and overall score obtained with the quality of life questionnaire for mouth breathers at the seven assessed fields.

\begin{tabular}{|c|c|c|c|c|c|}
\hline Field's & Lowest value & Highest value & Median & Mean & Standard deviation \\
\hline Nose problem & 0 & 52 & 17.00 & 18.08 & 10.73 \\
\hline Sleeping problem & 0 & 51 & 19.00 & 20.34 & 11.95 \\
\hline Food & 0 & 35 & 15.00 & 13.98 & 7.98 \\
\hline Dentition / esthetic & 0 & 26 & 10.00 & 10.29 & 6.27 \\
\hline Education & 0 & 18 & 6.00 & 5.99 & 4.42 \\
\hline Communication & 0 & 47 & 21.00 & 18.51 & 11.69 \\
\hline Atopy & 0 & 48 & 15.00 & 16.41 & 11.96 \\
\hline Overall score & 0 & 241 & 102.00 & 103.61 & 48.07 \\
\hline
\end{tabular}

Table 6 - Prevalence of the main questions related to the nose-problems and sleep-problems fields reported by the MB group (adapted from Ribeiro ${ }^{11}$ ).

\begin{tabular}{ccc}
\hline Nose problems field & Frequency (\%) & Sleep problems field \\
\hline Do you have any nasal problems? & 32.00 & Do you have any sleeping problems? \\
\hline Does your nose bother you? & 30.00 & Is your sleep usually restless? \\
\hline Do you often feel a stuffy nose? & 32.27 & Do you wake up during the night? \\
\hline Do you often sneeze? & 32.27 & 31.00 \\
\hline Do you present any nose itching? & 22.78 & Do you often complain of being sleepy during the day? \\
\hline Do you ever have a runny nose? & 17.72 & Do you sleep with your mouth open? \\
\hline Do you snore at night? & 19.62 & Have you ever stopped breathing while sleeping? \\
\hline Do you ever feel your mouth or throat itch? & 23.41 & Do you ever wake up with a headache? \\
\hline
\end{tabular}

and mouth breathing during clinical examination of children with suspected SDB. In the present study, long face pattern (dolichofacial), convex profile and absence of lip seal were predominant in $\mathrm{MB}$ children.

The main morphological changes found were: atresic palate, anterior open bite, posterior crossbite and excessive overjet. These malocclusions are mainly caused by an imbalance between forces exerted by the tongue, lips and the perioral muscles. ${ }^{16,17}$ In the MB group, atresic palate and overjet equal to or greater than $3 \mathrm{~mm}$ were more prevalent. A V-shaped palatal arch, with maxillary width equal or smaller than the mandible, was classified as an atresic palate. Some schoolchildren showed several concurrent morphological changes.

The mirror test ${ }^{18,19,20}$ helped to detect the presence of upper airway obstruction and the predominant breathing pattern (whether nose-breather or mouth breather). However, the water retention tests were important in 
determining the differential diagnosis between obstructive mouth breathing and an acquired habit of mouth breathing after temporary obstruction. The consequences associated with morphological changes will be the same, but knowing the cause for mouth breathing (whether obstruction or habit) provides the most effective treatment for the child.

The lip seal test (51.5\%) and the water retention test (53.9\%) for 3 minutes in the MB group revealed there was a slight predominance of mouth breathing habits in comparison to obstructive mouth breathing.

Only the MB group completed "The mouth breather quality of life questionnaire" to determine schoolchildren self-perception of their quality of life, as recommended by Ribeiro. ${ }^{11}$ The authors of the present study tried to encourage the participation of children, believing that there is information that only they could provide and thus be closer to their reality. The American Academy of Pediatrics ${ }^{1}$ and other pediatric organizations recommend the involvement of children and direct questioning about their health conditions and functions, mainly for those over the age of $6 .{ }^{21}$

According to the questionnaire, $54 \%$ of schoolchildren quality of life self-perception was considered good, with below-average scores and mostly negative answers. This result is not surprising and can be supported by school attendance records and children's good health. However, $46 \%$ of those children had a negative quality of life self-perception. The most expressive results were those related to sleeping problems and nose-related problems. These schoolchildren reported having the feeling to stop breathing while asleep, waking up with headache, having daytime sleepiness, sleeping with an open mouth, waking up with dry mouth, runny nose, snore, stuffy nose and sneezing. According to Palombini, ${ }^{2}$ Palombini et al, ${ }^{3}$ and Guilleminault et $\mathrm{al},{ }^{4}$ these are some of the major symptoms of SDB during childhood.

Popoaski et $\mathrm{al}^{22}$ also applied a quality of life questionnaire adapted from Ribeiro. ${ }^{11}$ They found that sleepproblem and nose-problem fields were the ones with greater scoring, thereby suggesting that these fields can negatively affect the quality of life of mouth breathers. In their study, ${ }^{22}$ the prevalence of trouble while asleep was nearly three times greater than in the study by Ribeiro. ${ }^{11}$
Although most schoolchildren reported having good self-perception of their quality of life, the prevalence of signs and symptoms related to SDB during childhood was high in the present study. According to ZettergrenWijk et al, ${ }^{23} \mathrm{SDB}$ in young children has an unfavorable effect on the development of several dental and facial components. However, if SDB is diagnosed and treated at an early age, nearly complete normalization of dentofacial morphology may be achieved.

Due to the negative repercussion of mouth breathing and its close relation to functional and morphological facial changes that favour SDB during childhood, the implementation of policies to prevent breathing problems is of particular relevance, as clearly evidenced by our results. These preventive measures must be set to provide proper nasal breathing via orthodontic and otolaryngological treatment, so as to develop educational guidance strategies and to stimulate healthy habits that might avoid mouth breathing. Furthermore, signs and symptoms related to SDB in children should be carefully investigated to justify the need for referrals to specific diagnostic exams.

\section{CONCLUSION}

" The prevalence of functional and morphological facial changes was considerably high among all schoolchildren assessed, mainly in those diagnosed as mouth breathers (MB).

» The most prevalent alterations found in $\mathrm{MB}$, in order of prevalence, were: deviated or swollen nasal septum; atresic palate; hypertrophic tonsils; lip incompetence; dolichofacial pattern; excessive overjet; anterior open bite; Mallampati classes III and IV; and posterior crossbite.

» Self-perception of children's quality of life was considered good for most MB schoolchildren despite the high prevalence of SDB symptoms reported, mainly those related to nasal and sleep problems.

\section{Acknowledgements}

The authors acknowledge Fundação de Amparo à Pesquisa do Espírito Santo (FAPES) for their financial support. 


\section{REFERENCES}

1. American Academy of Pediatrics. Clinical practice guideline: diagnosis and management of childhood obstructive sleep apnea syndrome. Pediatrics. 2002;109(4):704-12

2. Palombini LO. Diagnostic criteria and treatment for sleep-disordered breathing: RERA. J Bras Pneumol. 2010;36(supl. 2):19-22

3. Palombini L, Lopes M, Tufik S, Guilleminault C, Bittencourt LR. Uppe airway resistance syndrome: still not recognized and not treated. Sleep Sci. 2011;4(2):72-8.

4. Guilleminault C, Lee JH, Chan A. Pediatric obstructive sleep apnea syndrome. Arch Pediatr Adolesc Med. 2005;159(8):775-85.

5. Palombini L, Pelayo R, Guilleminault C. Efficacy of automated continuous positive airway pressure in children with sleep-related breathing disorders in an attended setting. Pediatrics. 2004;113(5):412-7.

6. Dayyat E, Kheirandish-Gozal L, Sans CO, Maarafeya MM, Gozal D. Obstructive sleep apnea in children: relative contributions of body mass index and adenotonsillar hypertrophy. Chest. 2009;136(1):137-44.

7. Sinha D, Guilleminault C. Sleep disordered breathing in children. Indian J Med Res. 2010;131:311-20

8. Chen W. Kushida CA. Nasal obstruction in sleep-disordered breathing. Otolaryngol Clin N Am. 2003;36(3):437-60.

9. Huynh NT, Morton PD, Rompré PH, Papadakis A, Remesi C. Associations between sleep-disordered breathing symptoms and facial and dental morphometry, assessed with screening examinations. Am J Orthod Dentofacial Orthop. 2011;140(6):762-70

10. Villa MP, Malagola C, Pagani J, Montesano M, Rizzoli A, Guilleminault C, et al. Rapid maxillary expansion in children with obstructive sleep apnea syndrome 12-month follow-up. Sleep Med. 2007:8(2):128-34

11. Ribeiro ML, Pinto JA. Qualidade de vida no respirador oral: avaliação sistemática em crianças de 6 a 12 anos, atendidas em centro de referência da UFMG [dissertação]. Minas Gerais: Universidade Federal de Minas Gerais; 2006.

12. Ribeiro ML. Validação do questionário de qualidade de vida e avaliação do bemestar subjetivo de crianças respiradoras orais [tese]. Belo Horizonte: Universidade Federal de Minas Gerais; 2012
13. Brodsky L. Modern assessment of tonsils and adenoids. Pediatric Clin North Am. 1989;36(6):1551-69

14. Mallampati SR, Gatt SP, Gugino LD, Desai SP, Waraksa B, Freiberger D, et al. A clinical sign to predict difficult tracheal intubation: a prospective study. Can Anaesth Soc J. 1985:32(4):429-34.

15. Samsoon GLT, Young JRB. Difficult tracheal intubation: a retrospective study. Anaesthesia. 1987:42(5):487-90.

16. Luzzi V, lerardo G, Viscogliosi A, Fabbrizi M, Consoli G, Vozza I, et al. Allergic rhinitis as a possible risk factor for malocclusion: a case-control study in children Int J Paediatr Dent. 2013;23(4):274-8.

17. Min-Ho J, Won-Sik Y, Dong-Seok N. Maximum closing force of mentolabial muscles and type of malocclusion. Angle Orthod. 2010;80(1):72-9.

18. Pochat VD, Alonso N, Mendes RRS, Cunha MS, Menezes JVL. Nasal patency after open rhinoplasty with spreader grafts. J Plastic Reconst Aesthetic Surg. 2012;65(6):732-38.

19. Zastrow MD, Grando LJ, Carvalho AP, Rath IBS, Calvo MC. A comparative study of the breathing pattern and amount of nasopharynx obstruction by the pharyngeal tonsil in HIV infected and non-infected children. Braz J Otorhinolaryng. 2007:73(5):583-91.

20. Motta LJ, Bachiega JC, Guedes CC, Laranja LT, Bussadori SK. Association between halitosis and mouth breathing in children. Clinics. 2011:66(6):939-42.

21. Riley AW. Evidence that school-age children can self-report on their health. Ambul Pediatrics. 2004;4(4):371-6.

22. Popoaski C, Marcelino TF, Sakae TM, Schmitz LM, Correa LHL. Evaluation from the quality of life in the oral breathers patients. Int Arch Otorhinolaryngol. 2012;16(1):74-81.

23. Zettergren-Wijk L, Forsberg CM, Linder-Aronson S. Changes in dentofacial morphology after adeno-/tonsillectomy in young children with obstructive sleep apnoea - a 5-year follow-up study. Eur J Orthod. 2006:28:319-26. 